\title{
Teaching Mode Reform Summary of Electronic Technology Application Major
}

\author{
Jiangming Kuang and Jiangping Zhang \\ The Engineering \& Technical College of Chengdu University of Technology, Leshan, 614000, P.R. \\ China
}

291806757@qq.com,35758905@qq.com

Keywords: Teaching mode; Electronic technology; Engineering majors; Electronics

\begin{abstract}
In this study, by analyzing the existing secondary vocational education teaching mode, we find quite a few inadaptable points according to the vocational education characteristics of engineering majors. For this reason, we focus on the target of training the engineering skilled talents better, to develop the teaching mode reform scheme of the electronics major and to boldly reform teaching in space organization and time organization. In 2009-2016 school years, the new teaching mode was piloted in the classes majoring in the electronics.
\end{abstract}

\section{Introduction}

Electronics major is our traditional major of our school. In years of teaching practice and research, I find that the traditional secondary education teaching mode has not improved the teaching quality fundamentally. Therefore, our school decides to organize teaching management personnel to study and explore according to training objectives and teaching characteristics of the electronics major and in combination with our school's teachers, equipment and area and other actual situations, so as to greatly improve the teaching quality and achieve our own vocational education features through the teaching mode reform.

By analyzing the existing secondary vocational education teaching mode, we find quite a few inadaptable points according to the vocational education characteristics of engineering majors. For this reason, we focus on the target of training the engineering skilled talents better, to develop the teaching mode reform scheme of the electronics major and to boldly reform teaching in space organization and time organization. In 2009-2016 school years, the new teaching mode was piloted in the classes majoring in the electronics.

\section{Problems and Reasons in Teaching of Electronic Technology Application Major}

Teaching of electronic technology application major lags behind the social and market needs. This is the main problem faced by the professional teaching. At present, the teaching situation of the electronic major is: first, the professional teachers seriously lack and insufficient related courses are offered; second, the electronic equipment in practice teaching often lags behind that of the enterprises; third, relevant teaching software lacks and there are no suitable high-quality teaching textbooks, furthermore, teaching modes are different. As an imported technology, the electronic technology has rapidly developed along with the information technology. Enterprises introduce various sophisticated electronic equipment unceasingly in the production, so they put forward higher skill requirements for the operator. Lag of teaching conditions produces varying effects on teaching of electronic technology application major; it is difficult for teachers to teach and, it is also difficult for students to learn. In addition, the new electronic training base's construction cost is too high and the school education funds are limited, so the vocational education keeps pace with the development of new technologies difficultly.

The reasons for the above problems include: 
1 After China joined the WTO, domestic enterprises have speeded up accepting international advanced technologies, and enterprises must continuously introduce all kinds of sophisticated electronic equipment in the production. At the same time, structure and size of the electronic equipment are very different, and each manufacturer's software is incompatible with others, so the higher requirements for teaching are raised.

2 Education fund is insufficient; updating of teaching facilities is too slow, and teaching and research lag. Because vocational schools have not used teaching resources mutually, their teaching resources are scattered and the existing teaching equipment conditions are quite different, device type is sole and no high quality textbooks are provided.

3 Teaching experience of the electronic technology major is insufficient and the teaching pattern needs to be improved. Teaching methods are not advanced; advanced teaching software lacks and global optimization of the training program is not desirable.

\section{Teaching Mode Reform of Electronic Technology Application Major}

In the face of the present teaching situation of the electronic technology major, by visiting employer, investigating the talent market of developed regions and exchanging with brothers schools in teaching of the electronic majors, the Vocational Education Center of Lianyungang city found out demands for the electronic professional talents, correctly analyzed the gap between the professional teaching and the practical production, grasped the electronic professional teaching orientation again, the following mode was preliminarily established in combination with the actual conditions of the school, namely the teaching mode with self-directed learning.

Self-directed learning is an effective learning way and an important learning ability; it will lay a foundation for lifelong learning of students, and it is beneficial to cultivate the students' ownership sense and sense of responsibility, to cultivate students' independent thinking and innovative spirit and to improve students' comprehensive quality. The teaching mode with self-directed learning adapts to the needs of social development; it is the need of educational development and also the need of students' individual development. As a kind of teaching mode, self-directed learning involves many teaching links in the implementation process. On the basis of characteristics of electronic information engineering major, the following six aspects are considered to create conditions and provide guarantee for the development of self-directed learning.

Training High-Quality Teaching Staff. As the direct organizer of teaching activities, a team with high-quality teaching staff is the important guarantee to improve the education quality. To develop teaching mode with self-directed learning, teachers need to change their concepts firstly, further improve their own education theoretical levels and integrate the self-directed learning theory with various specialized courses' teaching in combination with majors' characteristics and student's actual situations. In addition, the self-directed learning is not self-study, even not to let them go. To successfully carry out teaching activities with self-directed learning, on the one hand, teachers are required to overcome fixed thinking; on the other hand, teachers should carefully complete teaching design according to phase characteristics of self-directed learning in the teaching design; it is an on-going process in groping. It is thus clear that, the teaching mode with self-directed learning offers higher requirements for teachers than the traditional teaching mode. Professional teaching team and the high-quality teaching staff are personnel guarantee for developing self-directed learning successfully.

Deepening Teaching Content Reform and Building Reasonable Curriculum System. Electronic technology application major is multi-disciplinary integration, so students must possess a wide professional knowledge, higher humanity and technical quality and operational ability, master basic knowledge of electronics disciplines, and they should have basic theoretical attainment, specialized knowledge and basic skill in information collection and processing, transmission, transformation, detection, integration and basic system realization, rigorous training in engineering practice and preliminary scientific research training. Furthermore, they must participate in rigorous engineering practice training and preliminary scientific research training. 
Reform of the Classroom Teaching Methods and Effective Participation in Students' Out-Of-Class Learning. The Ministry of Education explicitly pointed out the policy of "promoting the credit system, reducing the proportion of compulsory courses, increasing the proportion of optional courses, reducing classroom teaching hours, increasing time and space of students' self-directed learning, broadening students' knowledge scope, enhancing students' learning interest, improving students' knowledge structure and promoting students' individuality development". Combined with course teaching of electronic technology application major, "reducing lecture hours" is one of the most difficult steps in the classroom teaching reform. The self-directed learning mode can solve the problem better. Self-directed learning enables students to learn actively from receiving learning, and changes the role of teachers passing on knowledge; as the organizer, tutor and promoter of the students in their study, teachers should implement targeted guidance and teaching based on specific characteristics of all aspects of students' self-directed learning. As extension and supplement of classroom teaching, in the strict sense, out-of-class learning is more convenient to carry out self-directed learning; therefore, teachers should participate in student's out-of-class learning, develop extracurricular resources fully by means of abundant information technology, create good learning situations for students and establish a good information communication platform between teachers and students.

Reform of Practice Teaching Mode. In teaching of the electronic technology application major, practical and theoretical aspects supplement each other, and none is dispensable. Practice is essential to cultivate students' practical ability. According to the curriculum system setting, in the same module experiment courses should be taken into overall consideration, for example, contents of Fabrication of Electrical Circuits and Debugging, Fabrication and Debugging of Analog Circuit and Fabrication and Debugging of digital circuit should take into overall consideration, the project teaching, unified planning of contents, establishing all kinds of experimental lessons, more reasonable distribution of experimental time, more systemic knowledge system. If the traditional teaching mode is continuously used for practice teaching of a separate class, it is bound to affect success of the teaching reform. It is necessary to carry out practice teaching with self-directed learning mode and further deepen the reform of practice teaching. Practice teaching with self-directed learning mode of must start with such aspects as teaching staff, experiment teaching content, method, means and management and experimental teaching mode, so as to let each student really participate in practice teaching, improve their practice ability and innovation spirit through practical training. To establish secondary vocational off-campus practice base and the innovation experiment base and to attend electronic skills contest and innovation competition, can provide a platform linking theory with practice; it can also promote the students' enthusiasm in participating in the practical training.

Textbook Compilation. In the existing teaching mode, the students use unified teaching textbooks, teachers lecture according to the teaching textbook content, but the students' levels could not be uniform, so the unified teaching textbooks are not beneficial to effective learning of students with different learning levels. When the self-directed learning theory is used in theory teaching and practice teaching activities, if the problem of unified teaching textbooks can not solved, it is bound to affect the in-depth development of self-directed learning. By using rich information resources in the information age, teachers provide a variety of appropriate learning materials in the teaching activities, or guide students to adopt related data suitable for them, publish school-based teaching textbooks suitable for the students in our school, so as to meet the needs of students with different levels; only this can achieve teaching according to their ability in the real sense.

Establishment of Assessment System for Self-Directed Learning. In evaluating self-directed learning, attention should be paid to process evaluation, and not only to inspection and testing of students' scholastic attainment; the evaluation results should become the motivation of students' further learning. This evaluation system should be geared to the needs of the students' future development, focus on students' long-term needs in lifelong learning and development, and serve for students' learning. Evaluation content should be comprehensive and integrate, with comprehensively inspection of self-directed learning motivation, learning content, learning time, learning methods, learning process and learning results and learning environment, etc. Both evaluation parties should emphasize 
cooperation and exchanges, stimulate students' subject consciousness in the evaluation activity, give play to autonomiation; teachers should focus on guiding students to perform self-assessment, including how to carry out self-examination, self-summary, self-reinforcement, and so forth. The evaluation results should be regarded as important reference to check whether the teaching instruction is effective.

\section{References}

[1] 'UPSs (Uninterruptible Power Supplies) Provide Reassurance in the Information Society," The Japan Electrical Manufacturers' Association (2009) in Japanese.

[2] "Guidelines for Energy Efficient Data Centers," The Green Grid, http://www.thegreengrid.org/home

[3] Ministry of Internal Affairs and Communications, "Report of the Research Committee on ICT Policies for Dealing with the Problem of Global Warming" (Apr. 2008) in Japanese.

[4] M. Toyota, "Technologies for Higher Efficiency and Smaller Size in Large Data Center UPSs," Electrical Review (Mar.2003) in Japanese.

[5] M. Tobise et al., "Inverter-Fed AC Drive Systems for Steel Rolling Mills," Hitachi Review 45, pp. 299-304 (Oct.1996).

[6] N. Hasegawa et al., "Saving Energy and Alternative Energy Solutions Contributing to the Water Environment," Hitachi Hyoron 89, pp. 610-615 (Aug. 2007) in Japanese.

[7] Y. Iwaji et al., "Evaluation of Characteristics of Predictive PWM Control," 1997 National Conference of the Institute of Electrical Engineers of Japan, in Japanese.

[8] K. Isihikawa et al., "Rolling Stock Inverters Using SiC Diodes," 46th Railway Cyber Symposium, 506, (Nov. 2009) in Japanese.

[9] M. Shigyo et al., "Inverter-fed AC Drive Systems for Hot Rolling Mills," Hitachi Hyoron 90, pp. 1014-1017 (Dec. 2008) in Japanese.

[10] M. Hagiwara et al., "Control and Experiment of Pulse width Modulated Modular Multilevel Converters," IEEE Transactions on Power Electronics (July 2009). 